\title{
FENOMENA TRANSPORT KOBALT-60 PADA LAPISAN TANAH
}

\author{
NGASIFUDIN \\ Pusat Teknologi Akselerator dan Proses Bahan \\ Jl.Babarsari Kotak Pos 1008, Yogyakarta 55010 \\ Telp. 0274488435 Faxs 487824
}

\begin{abstract}
Abstrak
FENOMENA TRANSPORT KOBALT-60 PADA LAPISAN TANAH. Telah dilakukan penelitian tentang fenomena gerakan Kobalt-60 (Co-60) pada lapisan tanah yang dilakukan secara kolom dan batch. Penggabungan Co-60.dengan tanah dan komponennya dipelajari dengan serangkaian teknik ekstraksi. Gambaran konsentrasi Co60 di dalam kolom tanah tersusun oleh dua kurva logaritma yang menunjukkan Co-60 terdiri atas fraksi gerak dan tidak-gerak. Fraksi Co-60 tidak-gerak diserap oleh tanah dan didistribusikan di dekat bagian atas kolom. Meskipun Co-60 fraksi gerak hanya sedikit terserap oleh tanah dan di-transportkan melalui kolom tanah, konsentrasi maksimum Co60 di dalam efluen sedikit menurun dengan kenaikan panjang kolom tanah. Ekstraksi Co-60 dari tanah dan komponennya menunjukkan bahwa Co-60 diserap oleh mangan dioksida dan komponen lempung. Mangan oksida merupakan salah satu komponen tanah yang dapat menurunkan konsentrasi maksimum Co-60 di dalam efluen. Bahkan kandungan mangan oksida 0,24-0,29\% dalam tanah menjadi komponen penting untuk mencegah proses transport Co-60 pada larutan keasaman rendah.
\end{abstract}

Kata kunci : Fenomena transport, Kobalt-60, komponen tanah

\begin{abstract}
TRANSPORT PHENOMENON OF COBALT-60 IN THE SOIL LAYER. The transport phenomena of cobalt-60 (Co-60) in the soillayer has been investigated using column and batch methods. The association of Co-60 with soil and its components were studied by extraction methods. The concentration profile of Co-60 in the soil column was composed of two logarithmic curves that showing Co-60 would be consist of mobile and immobile fraction. The immobile fraction of Co-60 was adsorbed by soil and was distributed near in the top of column. Although the mobile Co-60 was little sorbed by soil and migrated through the soil column, the maximum concentration of Co-60 in the effluents decreased slightly with increasing length of the soil column. Extraction of Co-60 from the soil and from its components showed that Co-60 was sorbed by manganese oxide and clay minerals. Manganese oxide is one of the soil components that could be decrease the maximum concentration of Co-60 in the effluents. Although the content of manganese oxide in the soil was $0.24-0.29 \%$, manganese oxide is the important component to prevent the migration of Co-60 in the low acidic solution.
\end{abstract}

Keywords : Transport phenomenon, Cobalt-60, soil component 


\section{PENDAHULUAN}

Proses transport radionuklida melalui lapisan tanah adalah satu dari banyak hal penting untuk mengevaluasi dampak penanganan limbah radioaktif di lingkungan. Harga koefisien distribusi untuk Kobalt-60 (Co-60) pada berbagai jenis tanah telah banyak ditentukan karena Co-60 merupakan salah satu radionuklida terpenting yang terkandung di dalam limbah radioaktif ${ }^{[1]}$. Penyebaran radionuklida dari lokasi instalasi nuklir ke lingkungan harus selalu dipantau agar pencemaran lingkungan menjadi sekecil mungkin. Pemantauan dan pengelolaan limbah radioaktif latar rendah biasanya dilakukan dengan jalan memantau air laut dan tanah serta permukaannya. Pada proses pengelolaan limbah radioaktif latar rendah, sifat-sifat transport atau perpindahan radionuklida pada lapisan tanah sangat penting untuk diketahui.

Pada umumnya proses sementasi telah banyak digunakan untuk pengolahan dan pemadatan limbah radioaktif latar rendah. Kemungkinan yang terjadi pada penyimpanan limbah di bawah tanah adalah perpindahan zat cair ke lapisan tanah sekitar, dan diperkirakan $\mathrm{pH}$ fase cairnya menjadi alkalis. Kondisi $\mathrm{pH}$ akan mempengaruhi proses perpindahan radionuklida pada lapisan $\operatorname{tanah}^{[2]}$. Proses interaksi antara larutan dengan padatan suatu radionuklida berhubungan dengan prinsip serapan atau sorpsi. Sedangkan kecepatan dan mekanisme sorpsi sangat dipengaruhi oleh media adsorben dan adsorbatnya ${ }^{[3]}$. Dilaporkan juga bahwa persentasi sorpsi Cobalt oleh oksida logam seperti $\mathrm{SiO}_{2}, \mathrm{TiO}_{2}$ dan mineral kaolin ${ }^{[4]}$ akan naik dengan kenaikan $\mathrm{pH}$ larutan. Beberapa tahun terakhir ini dari literatur-literatur ${ }^{[5-10]}$ terlihat bahwa para peneliti semakin banyak menggunakan model matematis dalam mempelajari transport radionuklida.

Sifat gerakan perpindahan konsentrasi Co-60 di dalam tanah kemungkinan akan dipengaruhi oleh keasamaannya, komposisi kandungan mineral tanah dan juga proses sorpsi dan transport antara Co-60 dengan tanah. Tujuan penelitian ini adalah untuk menentukan pengaruh $\mathrm{pH}$ terhadap karakteristik transport Co-60 sehingga akan diperoleh sifat transport radionuklida Co-60 di dalan tanah.

\section{METODE PENELITIAN}

\section{Bahan}

Bahan yang dipergunakan adalah sebagai berikut sampel tanah, larutan Co60, larutan $\mathrm{CoCl}_{2}$, aquades, glass wool, pecahan kaca, larutan $1 \mathrm{M}$ 
$\mathrm{CH}_{3} \mathrm{COONH}_{4}$, larutan $\mathrm{CH}_{3} \mathrm{COOH}$ pada $\mathrm{pH} 5$, Larutan $1 \mathrm{M} \mathrm{NH} \mathrm{NH}_{2} \mathrm{OH} \cdot \mathrm{HCl}$ yang mengandung $\mathrm{CH}_{3} \mathrm{COOH} 25 \%$, Larutan $\mathrm{CH}_{3} \mathrm{COONa}$, Larutan hidroksilamin.

\begin{abstract}
Alat
Peralatan yang dipergunakan adalah sebagai berikut pemanas (oven), peralatan penggerus, peralatan pengayak, neraca analitis, peralatan gelas, pipet tetes, penggaris, buret, statip, stop watch, Alat cacah LBC, tabung kolom gelas, pengaduk listrik, lampu pengering.
\end{abstract}

\title{
Cara Kerja
}

1. Preparasi Tanah

a. Pengeringan sampel tanah

Sampel tanah diambil dari kedalaman 0-30 cm. Masing-masing sampel tanah dimasukkan ke dalam mangkok yang telah diberi tanda tempat pengambilan tanah dan ditimbang. Sampel tanah dimasukkan ke dalam oven selama 7 jam pada suhu $105^{\circ} \mathrm{C}$. Setelah dioven sampel tanah ditimbang dan kemudian dipanasi lagi. Proses di atas diulangi lagi sampai diperoleh berat sampel tanah konstan.

b. Penggerusan dan pengayakan sampel tanah

Sampel tanah yang sudah kering digerus sampai diperoleh ukuran kerikil kasar. Sampel tanah digerus lagi setelah kerikil kasarnya dipisahkan memakai ayakan kasar. Saringan yang akan dipakai dibersihkan terlebih dahulu. Saringan yang sudah bersih disusun dengan urutan susunan sebagai berikut : paling bawah ayakan dengan diameter $75 \mu \mathrm{m}$, kemudian di atasnya dengan diameter $150 \mu \mathrm{m}, 180$ $\mu \mathrm{m}$, dan $250 \mu \mathrm{m}$. Sampel tanah yang sudah digerus dimasukkan ke dalam mesin pengayak yang telah tersusun seperti di atas. Mesin pengayak dihidupkan selama 30 menit. Hasil pengayakan diambil dari masing-masing bagian pengayak sehingga diperoleh ukuran butiran $<75 \mu \mathrm{m}, 75-150 \mu \mathrm{m}, 150-180 \mu \mathrm{m}$ dan $>180 \mu \mathrm{m}$.

c. Penyiapan kolom tanah

Kolom gelas diisi pecahan kaca dan glass wool secukupnya. Sampel tanah yang telah diayak seberat 25 gr dimasukkan ke dalam kolom gelas. Tanah yang masuk kolom gelas dipadatkan dengan cara mengetok-ngetok pelan-pelan bagian luar dinding kolom gelas. Kolom gelas dipasang pada statip dan di atasnya dipasang buret.

d. Penjenuhan kolom tanah

Buret diisi aquades sampai penuh. Kran buret dibuka dan setelah aquades mengalir kedalam kolom tanah sebanyak $25 \mathrm{~mL}$ kran buret ditutup. Langkah-langkah di atas diulangi sampai kolom tanah jenuh, 
artinya tercapai suatu kondisi dimana jumlah aquades yang masuk ke dalam kolom tanah sama dengan jumlah aquades yang keluar.

e. Pembuatan larutan Kobalt-60

Digunakan $60 \mathrm{CoCl}_{2}$. Larutan influen $\mathrm{pH} 12$ dibuat dengan cara melarutkan ke dalam akuades dan konsentrasi Radionuklida 3,7× 103 $\mathrm{Bq} / \mathrm{mL}(100 \mathrm{nCi} / \mathrm{mL})$. Larutan influen pertama-tama dibuat $\mathrm{pH} 3$ dengan $\mathrm{HCl}$ untuk membebaskan karbonat, kemudian menjadi 12 dengan $\mathrm{NaOH}$. Konsentrasi kobalt dalam larutan influen adalah $1 \times 10^{-8} \mathrm{M}$.

2. Parameter Percobaan

a. Penentuan Koefisien Distribusi dan Faktor Retardasi Kobalt pada kolom tanah.

Buret yang berisi aquades diambil dan diganti dengan buret lain yang diisi larutan Kobalt. Kran buret dibuka sehingga larutan Kobalt mengalir ke dalam kolom tanah. Debit aliran larutan Kobalt diatur dengan mengatur kran buret sehingga ketinggian larutan Kobalt senantiasa konstan. Larutan yang keluar dari kolom di tampung dengan vial yang telah diberi nomor urut dan diambil tiap 2,5 mL.

b. Pencacahan larutan efluen dari kolom tanah

Dipersiapkan planset dan diberi nomor sesuai dengan nomor urut keluaran larutan dari kolom tanah. Dari masing-masing sampel larutan keluaran kolom tanah diambil sebanyak $100 \mu \mathrm{l}$ dan dimasukkan ke dalam planset, kemudian dikeringkan memakai lampu pengering. Setelah kering masing-masing planset di cacah untuk diketahui aktivitasnya.

c. Percobaan Transport :

Sistem percobaan menggunakan kolom gelas diameter $5 \mathrm{~cm}$ dan tinggi $35 \mathrm{~cm}$ dan alat lainnya yang dirangkai ditunjukkan pada Gambar 1. 


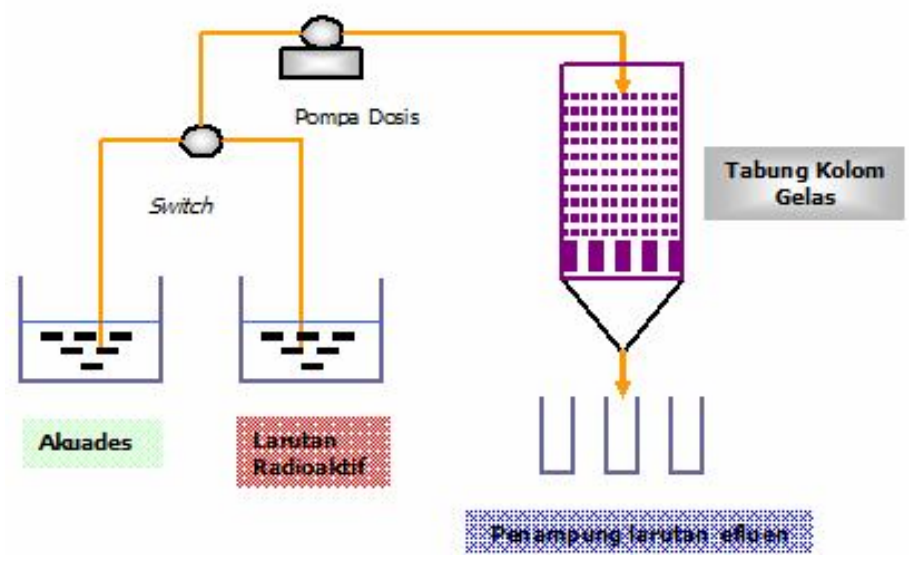

Gambar 1. Sistem Percobaan Transport

Tanah di pak ke dalam kolom setinggi $15 \mathrm{~cm}$. Di bagian bawah kolom tanah diberi pecahan gelas untuk menjaga aliran ekstra. Bulk densitas tanah dalam kolom adalah $1,66 \mathrm{~g} / \mathrm{cm}^{-3}$.

Setelah di dalam kolom tanah diperoleh aliran akuades konstan, larutan influen sebanyak $1000 \mathrm{~mL}$ dimasukkan ke dalam kolom melalui bagian atas, lalu kolom tanah dibilas lagi dengan 1000 $\mathrm{mL}$ akuades.

Kecepatan alir konstan $6,6 \times 10^{-2} \mathrm{~mL} /$ detik diatur dengan pompa tabung mikro. Kondisi ini dinamakan Tahap Acuan. Percobaan transport dilakukan dengan cara mengganti panjang kolom dari $15 \mathrm{~cm}$ menjadi $30 \mathrm{~cm}$ dan merubah jumlah larutan influen dari 1000 menjadi $500 \mathrm{~mL}$ untuk menguji pengaruh panjang kolom dan profil konsentrasi dari jumlah totalnya.

Radioaktivitas Co-60 ditentukan dengan gamma spektrometri. Sebanyak setiap $50 \mathrm{~mL}$ bagian efluen diambil, sedangkan tanah disampling setiap kedalaman $1 \mathrm{~cm}$. Metoda transmissi netron memberikan kecepatan air $0,012 \mathrm{~cm} /$ detik dalam kolom tanah dan rata-rata kandungan air tanahnya $0,35 \mathrm{~cm}^{3} / \mathrm{cm}^{3}$.

Konsentrasi Co-60 dalam efluen dan dalam sampel tanah dinormalkan terhadap larutan influen.

Konsentrasi relatif Co-60 dalam tanah (Cnorm):

$$
\mathrm{C}_{\text {norm }}=\rho\left(\mathrm{C}_{\text {tanah }} / \mathrm{C}_{\text {inf }}\right)
$$

dengan :

$\rho=$ bulk densitas tanah dalam kolom $\left(\mathrm{g} / \mathrm{cm}^{3}\right)$. 


$$
\begin{aligned}
& \text { Ctanah }=\text { konsentrasi Co-60 dalam tanah }(\mathrm{Bq} / \mathrm{g}) . \\
& \text { Cinf }=\text { konsentrasi Co-60 dalam larutan influen }(\mathrm{Bq} / \mathrm{mL}) .
\end{aligned}
$$

d. Percobaan Adsorpsi Batch :

Percobaan adsorpsi Co-60 dalam tanah dan komponen-komponennya dalam larutan pH 12 dilakukan secara batch untuk menguji kontribusi komponen-komponen terhadap sorpsi Co-60. Meskipun adsorpsi Co-60 oleh tanah memerlukan kesetimbangan dalam satu hari, $2 \mathrm{~g}$ tanah atau 0,5 g masing-masing komponennya dikontakkan untuk 1 minggu dengan larutan Co-60 sebanyak $50 \mathrm{~mL}$ yang mana kekuatan ion dan $\mathrm{pH}$ akan ekivalen dalam larutan influent.

e. Penggabungan Co-60 dengan komponen pada tanah berpasir :

Serangkaian ekstraksi dilaksanakan untuk menentukan penggabungan Co-60 dengan tanah yang berpasir dan komponen-komponennya pada larutan-larutan dengan $\mathrm{pH}$ 12. Percobaan rangkaian ekstraksi adalah sebagai berikut:

Tanah berpasir dan komponen-komponennya dikontakkan : Pertama dengan akuades, yang kedua dengan suatu larutan 1M $\mathrm{CH}_{3} \mathrm{COONH}_{4}$ pada $\mathrm{pH}$ 7, yang ketiga dengan larutan $\mathrm{CH}_{3} \mathrm{COOH}$ pada

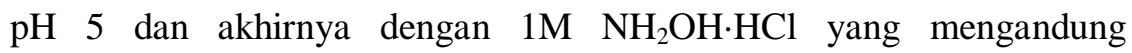
$\mathrm{CH}_{3} \mathrm{COOH}$ 25\%. Larutan $\mathrm{CH}_{3} \mathrm{COONH}_{4}$, larutan $\mathrm{CH}_{3} \mathrm{COONa}$ dan larutan hidroksilamin dipertimbangkan menyerap Co-60 yang terserap secara terbalik, berturut-turut Co-60 digabungkan dengan karbonat dan mangan dioksida. Sisa Co-60 dapat digabungkan dengan $\mathrm{FeOOH}$ dan atau dicampur dalam mineral yang berongga dan mineral yang liat.

Untuk ekstraksi, 1 gram sampel tanah pada 3 posisi kedalaman yang berbeda antara 0-2, 6-8 dan 12-14 cm dari kolom tanah pembanding. Tanah dan komponen-komponen pada Co-60 yang sudah diserap dalam sejumlah percobaan yang merupakan hal pokok dalam pengujian pengambilan ekstraksi untuk membandingkan ciri-ciri penyerapan bagi tanah berpasir dengan komponen-komponennya tersebut. Tanah dan komponen dihubungkan tiga kali dengan masingmasing alat pengekstraksi pada $50 \mathrm{~mL}$ selama 4 jam.

\section{HASIL DAN PEMBAHASAN}

Hasil analisis kimia tanah disajikan dalam Tabel 1. Terlihat kandungan Mangan oksida hanya 0,24-0,29\%. 
Tabel 1. Hasil Analisis Kimia Tanah (Satuan \% Berat)

\begin{tabular}{ccc}
\hline Oksida/unsur & $\begin{array}{c}\text { Lapisan 1 } \\
(0-5 \mathrm{~cm})\end{array}$ & $\begin{array}{c}\text { Lapisan 2 } \\
(5-10 \mathrm{~cm})\end{array}$ \\
\hline $\mathrm{SiO}_{2}$ & 38.76 & 39.99 \\
$\mathrm{Al}_{2} \mathrm{O}_{3}$ & 22.65 & 21.53 \\
$\mathrm{Fe}_{2} \mathrm{O}_{3}$ & 15.11 & 13.24 \\
$\mathrm{CaO}$ & 1.21 & 0.19 \\
$\mathrm{MgO}$ & 0.70 & 0.31 \\
$\mathrm{Na} O$ & 0.25 & 0.07 \\
$\mathrm{~K}_{2} \mathrm{O}$ & 0.56 & 0.20 \\
$\mathrm{MnO}$ & 0.24 & 0.29 \\
$\mathrm{TiO}_{2}$ & 1.50 & 1.35 \\
\hline
\end{tabular}

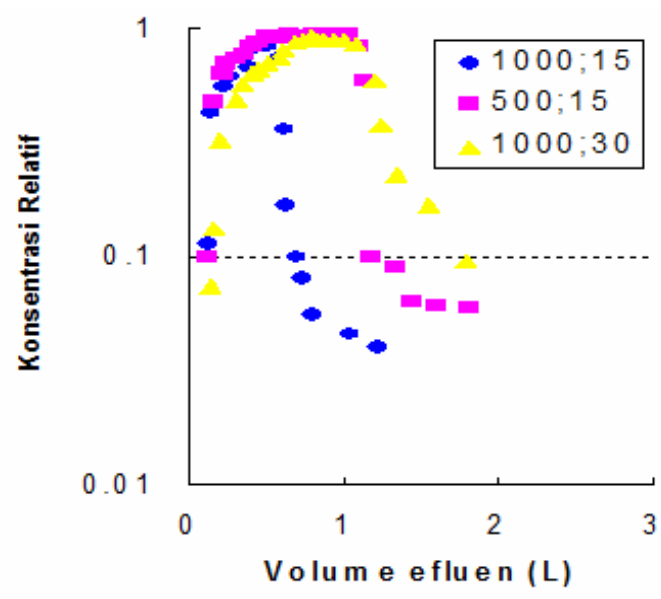

Gambar 2. Perubahan Konsentrasi Co-60 Normal Terhadap Volume Larutan Influen

\section{Sifat Transport Kobalt-60}

Sifat transport Co-60 dapat diterangkan dengan hubungan gambaran konsentrasi Co-60 normal terhadap volume larutan influen seperti terlihat pada Gambar 2 yang menunjukkan bahwa konsentrasi maksimum Co-60 pada efluen lebih rendah sekitar $10 \%$ daripada konsentrasinya pada larutan influen. Setelah berada dalam kondisi akuades, yaitu kondisi semua larutan radioaktif (influen) telah melalui kolom, maka konsentrasi Co-60 menurun sesuai waktu alir dan konsentrasinya naik 5\% dalam influen.

Kondisi pH pada larutan efluent bertambah tinggi sampai pH 12 dengan naiknya konsentrasi Co-60 dalam larutan influen, sedangkan setelah berada dalam kondisi akuades $\mathrm{pH}$ efluen turun secara perlahan-lahan sampai pH 6. Konsentrasi maksimum yang terukur dalam efluen melalui kolom tanah $30 \mathrm{~cm}$ adalah 0,83 lebih rendah daripada yang melalui kolom tanah 15 
$\mathrm{cm}$. Ini menunjukkan bahwa konsentrasi Co-60 dalam efluen turun dengan kenaikan jarak transport.

Gambaran konsentrasi Co-60 pada kolom tanah yang dipilih setelah jenuh menghilangkan Co-60 dalam air tanah menunjukkan suatu penurunan awal yang cepat dengan kenaikan kedalaman, melewati lebih dari penurunan gradual dengan kedalaman lebih dari 5-6 cm seperti yang ditunjukkan pada Gambar 3.

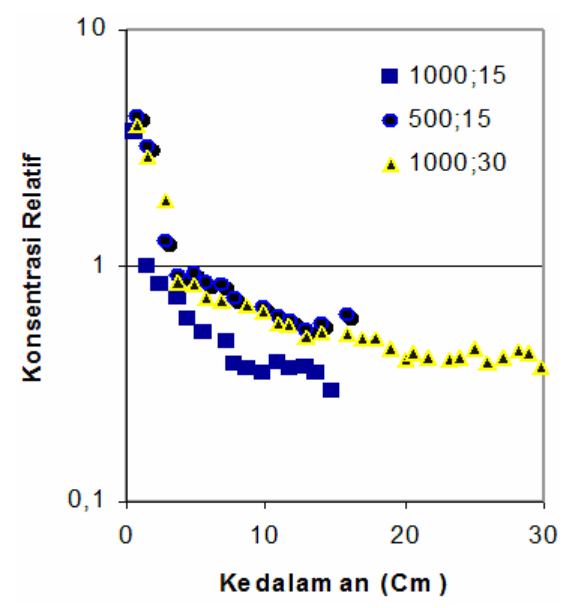

Gambar 3. Perubahan Konsentrasi Co-60

Terhadap Kedalaman Lapisan Kolom Tanah

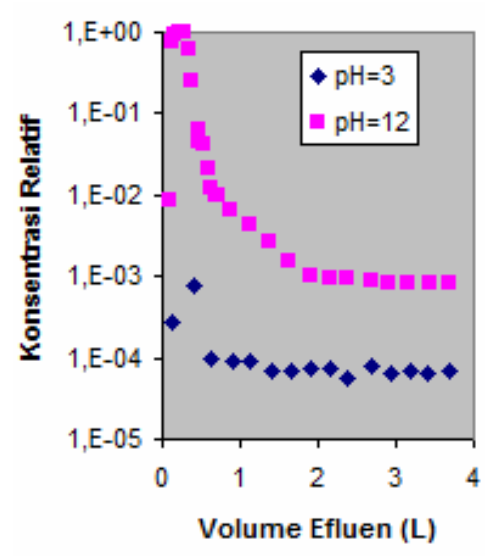

Gambar 4. Kurva Konsentrasi Relatif dan Volume Efluen Co-60 dari Tanah Pada pH 3 dan 12 


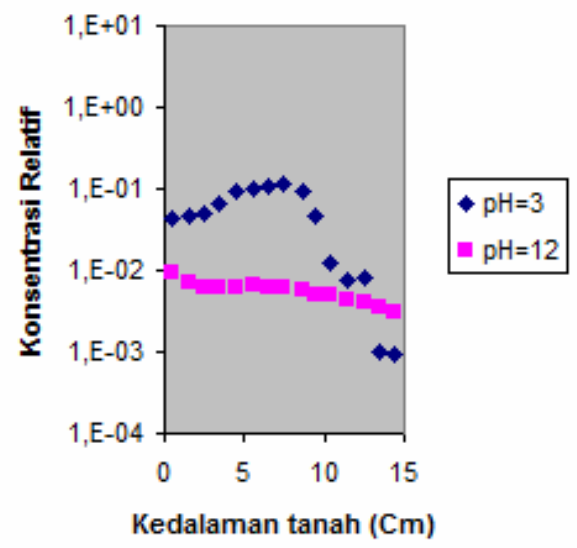

Gambar 5. Kurva Distribusi Konsentrasi Relatif Co-60 untuk Kedalaman Tanah pada pH 3 dan 12

Hubungan antara Konsentrasi Relatif Co-60 dengan Volume Efluen dan distribusi konsentrasinya terhadap Kedalaman Tanah disajikan pada Gambar 4 dan 5. Dari Gambar 4 terlihat bahwa konsentrasi Co-60 pada $\mathrm{pH} 12$ menurun drastis setelah volume $250 \mathrm{~mL}$, kemudian berkurang sedikit demi sedikit. Pada Gambar 5, distribusi konsentrasi Co-60 pada lapisan kolom tanah untuk pH 12 secara keseluruhan dapat dikatakan tidak jauh berbeda pada setiap kedalaman lapisan tanah. Sebaliknya dari Gambar 4, pada pH 3 konsentrasi Co-60 sejak aliran pertama berharga pada level 0,0001 dan selanjutnya konsentrasi Co-60 dalam efluen hampir sama. Dari Gambar 5, distribusi konsentrasi Co-60 dalam lapisan tanah pada $\mathrm{pH} 3$ diperoleh setelah kedalaman $7 \mathrm{~cm}$.

Dengan demikian dapat dikatakan bahwa Co-60 melakukan transport dengan kecepatan alir tinggi pada $\mathrm{pH} 12$, dan sebaliknya pada $\mathrm{pH} 3$ Co-60 hanya bergerak lambat dalam lapisan tanah karena konsentrasi Co-60 dalam efluen turun dengan kenaikan jarak transport akibat berkurangnya kandungan mangan oksida.

Perlakuan Penyerapan dan Penggabungan Co-60 dengan tanah berpasir dan komponen-komponennya

Harga Koefisien distribusi (KD) Co-60 bagi komponen tanah ${ }^{[11]}$ adalah $6,6 \times 10^{3} \mathrm{~mL} / \mathrm{g}$ untuk kaolin dan $4,9 \times 10^{3}$ untuk klorit dan $3,2 \times 10^{3}$ untuk todorolit, 810 untuk $\mathrm{FeOOH}$ dan 160 untuk rutile. Kobalt-60 lebih mudah diserap oleh kaolin, klorit dan todorolit daripada oleh $\mathrm{FeOOH}$ dan rutile karena KD untuk kaolin, klorit dan todorolit lebih tinggi beberapa kali daripada $\mathrm{KD} \mathrm{FeOOH}$ dan rutile. 
Bagian fraksi Co-60 yang diserap kembali dari tanah berpasir melalui rangkaian ekstraksi yang sudah disampel pada posisi yang berbeda pada 0-2, 6-8 dan 12-14 cm masing-masing ditunjukkan pada Gambar 6A-C.

(A)

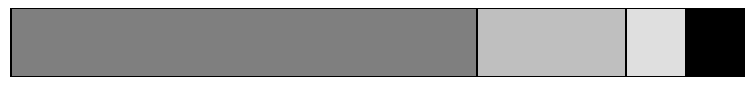

(B)

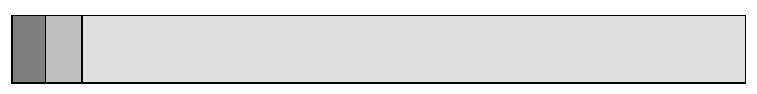

(C)

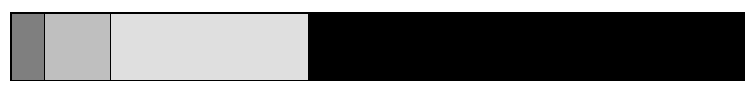

(D)

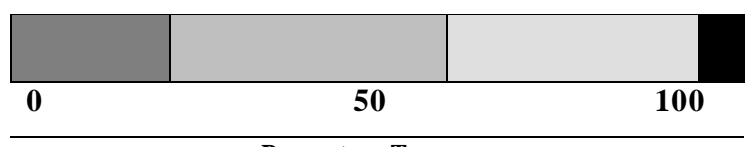

Persentase Terserap

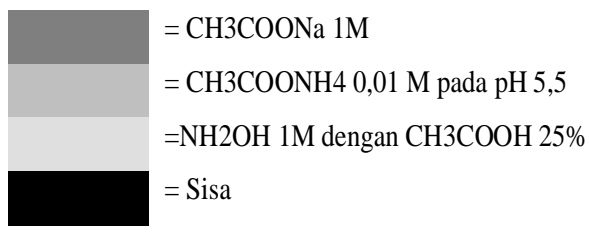

Gambar 6. Bagian Dari Co-60 Yang Diserap Kembali Pada Proses Ekstraksi. Tanah Disampel Pada Posisi Yang Berbeda Pada Kolom Tanah (A): Pada 0-2 Cm; (B) Pada 6-8 Cm; (C) Pada 12-14 Cm Dan (D) Co-60 Yang Diserap Kem,Bali Oleh Tanah Pada Beberapa Sistem

Gambar 6D memperlihatkan bagian fraksi Co-60 yang diserap kembali dari tanah yang mana Co-60 sudah diserap dalam sistem batch. Kurang dari 1\% Co-60 sudah diserap oleh tanah dengan akuades baik dalam kolom maupun batch. Hal ini menyatakan bahwa penggabungan Co-60 dengan tanah dalam sistem kolom tidak mempengaruhi kecepatan akuades.

Kira-kira $30 \%$ fraksi tak-gerak Co-60 yang diserap oleh larutan $\mathrm{CH}_{3} \mathrm{COONH}_{4}$ menjadi lebih tinggi dari pada fraksi gerak Co-60. Bagian fraksi yang lebih rendah pada fraksi tak-gerak Co-60 dilarutkan dengan hidroksilamin, larutan secara relatif menuju ke pada fraksi gerak Co-60. Penggabungan fraksi gerak Co-60 dengan tanah berpasir yang demikian mungkin berbeda dengan fraksi gerak Co-60.

Pada sisi lain, pola penyerapan kembali (desorpsi) bagi sampel tanah pada kedalaman 6-8 cm menyerupai pada kedalaman $12-14 \mathrm{~cm}$. Yang lebih menarik, kurang dari 5\% baik pada Co-60 fraksi tak-gerak maupun fraksi gerak sudah diserap oleh larutan $\mathrm{CH}_{3} \mathrm{COONa}$ pada $\mathrm{pH}$ 5. Jika Co-60 diendapkan sebagai Co-60 karbonat ${ }^{[12]}$, Co-60 karbonat seharusnya diserap 
kembali dengan larutan $\mathrm{pH}$ 5. Dengan begitu Co-60 fraksi tak-gerak dan fraksi geraknya tidak akan diendapkan sebagai Co-60 karbonat.

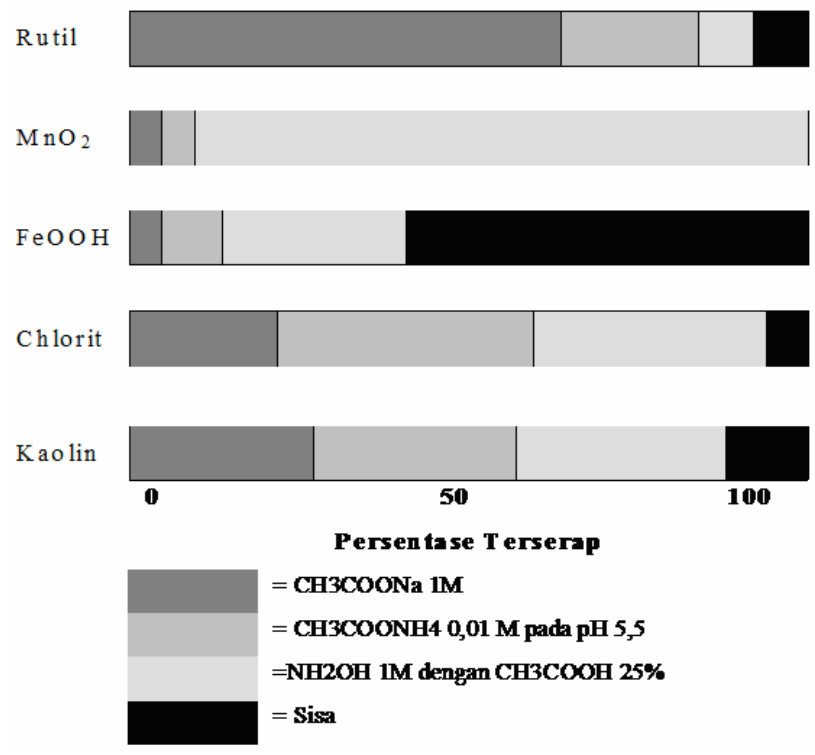

Gambar 7. Bagian Fraksi Co-60 Diserap Kembali Oleh Tiap-Tiap Komponen Pada Tanah

Gambar 7 menunjukkan bagian fraksi Co-60 diserap kembali oleh tiap-tiap komponen pada tanah berpasir. Lebih dari 50\% Co-60 diserap oleh kaolinit, khlorit, dan rutile sudah diserap kembali dengan larutan $\mathrm{CH}_{3} \mathrm{COONH}_{4}$ dan larutan $\mathrm{CH}_{3} \mathrm{COONa}$ pada $\mathrm{pH}$ 5. Sebagian kecil Co-60 diserap oleh todorolite, diserap kembali dengan $\mathrm{CH}_{3} \mathrm{COONH}_{4}$ dan larutan $\mathrm{CH}_{3} \mathrm{COONa}$ pada $\mathrm{pH}$, dan sebagian besar diserap kembali dengan larutan hidroksilamin.

Tujuh puluh lima persen Co-60 yang diserap oleh $\mathrm{FeOOH}$ tidak diserap kembali oleh beberapa mineral. Hal ini menyatakan bahwa dalam larutan pH 12 akan diserap kembali lebih kuat oleh mangan oksida dan besi oksida daripada oleh mineral liat dan rutile.

\section{KESIMPULAN}

1. Sifat gerakan perpindahan konsentrasi Co-60 di dalam kolom tanah tersusun oleh dua kurva eksponensial yang menunjukkan bahwa pada larutan $\mathrm{pH} 12$ akan terdiri atas dua fraksi transport yang berbeda, yaitu fraksi gerak Co-60 dan fraksi-tidak gerak Co-60. Konsentrasi maksimum Co-60 di dalam efluen berkurang dengan naiknya panjang kolom tanah. 
2. Di antara komponen-komponen tanah, Co-60 lebih terserap oleh kaolin, khlorit dan mangan oksida. Co-60 akan lebih terserap oleh mangan dioksida daripada lempung.

3. Pada proses ekstraksi menunjukkan bahwa Co-60 diserap oleh mangan oksida dan mineral lempung selama proses transport dalam kolom tanah. Dan mangan oksida mengkontribusi penurunan konsentrasi maksimum Co-60 di dalam efluen dengan kenaikan panjang kolom tanah.

4. Gerakan transport Co-60 mempunyai retardasi kecil dan fraksi geraknya tertentu terhadap tanah, yang berarti bahwa pada penggabungan Co-60 dengan tanah harga koefisien distribusi sangat penting untuk memperkirakan sifat transport Co-60 dalam tanah.

\section{DAFTAR PUSTAKA}

1. YAMAMOTO, T., et al., 1982, ”J. Jpn. Health Phys. Soc”., (in Japanese), 17,3.

2. TYLLER, K.G., et al., 1963, ”Soil Sci”., 95, 392.

3. HIGASHI, K., et al., 1980, "Analytical Models for Migration of Radionuclides in Geologic Sorbing Media”, J. Nuc. Sci. Technol., 17, 9.

4. JAMES, R.O., et al., 1972, “. Colloid Interface Sci”, 40, 42.

5. DLOUHY, Z., 1982, "Disposal of Radioactive Wastes", Elsevier Scientific Publ. Co., New York.

6. ERBANG, H., 1991, "Migration of Nuclides in the Environment", Regional Training Course for Asia and the Pasific Region on Environmental Monitoring and Assesment of Nuclear Facility, China Institute for Radiation Protection, Taiyuan, Shanxi.

7. GUVEN, R.W., 1985, "Analysis and Interpretation of Single-Well Tracer Test in Stratified Aquifer", Water Resourcer Research, Volume 21, May 1985 Number 5, American Geophysical Union.

8. HANS, B., 1982, "Nuclear Power the Environment and Man", Information Booklet Prepared Jointly by IAEA and WHO, Austria.

9. HARTMANN, R., 1980, "Methods for Soil Pyisical Analyses", State University of Gent, Faculty of Agricultural Sciences Department of Soil Physics, Gent.

10. HERBERT, F.W. and MARY,P.A., 1982, Introduction to Ground Water Modelling, W.H. Freeman and Company, San Fransisco.

11. DOUGLAS KILLEY, R.W., et.al., 1984, "Subsurface Cobalt-60 Migration from a Low Level Waste Disposal Site”, Environ. Sci. Technol., 18, 148 157.

12. CHESTER, R., et.al., 1981, “Techniques for Identifying Transuranic Speciation in Aquatic Environments", IAEA, 173. 